\title{
Bisphenol A Inhibits Cell Proliferation and Reduces the Motile Potential of Murine LM8 Osteosarcoma Cells
}

\author{
TERUKI KIDANI $^{1 *}$, RIE YASUDA ${ }^{2 *}$, JOJI MIYAWAKI ${ }^{1}$, YUSUKE OSHIMA $^{3}$, \\ HIROMASA MIURA ${ }^{1}$ and HIROSHI MASUNO ${ }^{2}$ \\ Departments of ${ }^{1}$ Bone and Joint Surgery, and ${ }^{3}$ Molecular Medicine for Pathogenesis, \\ Ehime University Graduate School of Medicine, Toon, Japan; \\ ${ }^{2}$ Department of Medical Technology, Faculty of Health Sciences, \\ Ehime Prefectural University of Health Sciences, Tobe, Japan
}

\begin{abstract}
Aim: The aim of this study was to examine the effect of bisphenol A (BPA) on the proliferation and motility potential of murine LM8 osteosarcoma cells. Materials and Methods: LM8 cells were treated for 3 days with or without $80 \mu M B P A$. The effect of BPA on cell proliferation was determined by DNA measurement in the cultures and 5-bromo-2'-deoxyuridine $(B r d U)$ incorporation study. Ethanol-fixed cells were stained with hematoxylin-eosin $(H \& E)$ to visualize cell morphology. Cell motility was assayed using inserts with uncoated membranes in invasion chambers. Expression of cell division cycle 42 (CDC42) was determined by immunofluorescence staining and western blotting. Results: BPA reduced the DNA content of cultures and the number of BrdU-positive cells. BPA induced a change in morphology from cuboidal with multiple filopodia on the cell surface to spindle-shaped with a smooth cell surface. BPAtreated cells expressed less CDC42 and were less motile than untreated cells. Conclusion: BPA inhibited DNA replication and cell proliferation. BPA inhibited filopodia formation and motile potential by inhibiting CDC42 expression in LM8 cells.
\end{abstract}

Bisphenol A (BPA) is an endocrine-disrupting chemical that is ubiquitous in the environment. For example, BPA is used commercially in products containing polycarbonate plastics, such as baby bottles, food and water containers, the linings of food and beverage cans, and dental fillings $(1,2)$. Microgram amounts of BPA are liberated from baby bottles when they are

*These Authors contributed equally to this study.

Correspondence to: Teruki Kidani, MD, Ph.D., Department of Bone and Joint Surgery, Ehime University Graduate School of Medicine, Toon, Ehime 791-0295, Japan. Tel: +81 899605343, Fax: +81 899605346, e-mail: teruteru@m.ehime-u.ac.jp

Key Words: Murine LM8 osteosarcoma cells, bisphenol A, cell proliferation, cell motility, filopodia formation, CDC42 expression. subject to simulated use by dishwashing, boiling, and brushing (1). Similarly, microgram amounts of BPA are found in the liquid of food preserved in cans (3) and in the saliva of dental patients treated with fissure sealants (4). A small amount of BPA is found in tap and lake water $(5,6)$, human serum $(2$, 7 ), and human breast milk (2). Therefore, it appears that BPA is routinely ingested by humans.

BPA mimics the actions of estrogens. Experimental and epidemiological studies have shown that BPA is associated with reproductive disturbance and metabolic disorders (2, 714). Prenatal exposure to BPA altered postnatal reproductive function and advanced puberty in female mice (8). In addition, similarly to $17 \beta$-estradiol, BPA promoted the growth of several types of tumor cells such as human estrogen-sensitive MCF-7 breast cancer cells $(4,15-17)$ and human SK-N-SH neuroblastoma cells (18). Other environmental estrogenic chemicals, such as 4-nonylphenol and 4-tert-octylphenol, also promoted the growth of MCF-7 cells $(19,20)$. In contrast, phytoestrogen genistein, which is found in soybean, inhibited the growth of tumor cells such as MCF-7 cells (21) and murine B16 melanoma cells (22).

Osteosarcoma is the most common malignant musculoskeletal tumor and occurs mainly in the metaphyseal region of long bones in young people $(23,24)$. Osteosarcoma frequently leads to development of micrometastases in the lung prior to diagnosis, and the subsequent development of metastatic tumors in the lung often causes a fatal outcome (24-26). Therefore, agents for preventing pulmonary metastases are critical for improving the prognosis of patients with osteosarcoma.

An LM8 osteosarcoma cell line with high metastatic potential to the lung was established from murine Dunn osteosarcoma cells without metastatic potential in $\mathrm{C} 3 \mathrm{H}$ mice (27). This cell line has been used as an excellent tool for studying inhibitory agents of pulmonary metastasis $(28,29)$. We previously found that genistein inhibited cell proliferation and reduced the motile potential of LM8 cells (30). 
In this study, the effect of BPA on the proliferation, motility, and invasion of LM8 cells was examined. In addition, we examined the relationship between the structure of bisphenols and the effect that they exert on cell proliferation using bisphenols with different substituents either on the central carbon atom between the two phenolic rings, or on the hydroxyl groups in the para position on the phenolic rings.

\section{Materials and Methods}

Cell line, reagents, and antibodies. LM8 cells (RBRC-RCB1450) were obtained from RIKEN BRC Cell Bank (Ibaraki, Japan). BPA, bisphenol B (BPB), bisphenol A diacetate (BPDA), bisphenol A dimethacrylate (BPDM), bisphenol A bis(chloroformate) (BPBCF), bisphenol A diglycidylether (BPDGE), and bisphenol A O,O-diacetic acid (BPDAA) were obtained from Tokyo Kasei Co. (Tokyo, Japan). Bisphenol E (BPE), bisphenol F (BPF), and 5-bromo-2'-deoxyuridine (BrdU) were obtained from Wako Pure Chemical Industries, Ltd. (Osaka, Japan). Bisphenols were dissolved in dimethyl sulfoxide. UltraCULTURE ${ }^{\mathrm{TM}}$ was obtained from Lonza Japan (Tokyo, Japan). PAGE blue was obtained from Cosmo Bio Co., Ltd. (Tokyo, Japan). 4',6-Diamidino-2phenylindole (DAPI) was obtained from Thermo Fisher Scientific (Osaka, Japan). A mouse monoclonal antibody to BrdU and a fluorescein isothiocyanate (FITC)-labeled anti-mouse $\mathrm{IgG}$ were obtained from Dako Japan Inc. (Tokyo, Japan). A rabbit polyclonal antibody to cell division cycle 42 (CDC42), a mouse monoclonal antibody to glyceraldehyde-3-phosphate dehydrogenase (GAPDH), and an Alexa Fluor $^{\circledR}$ 488-conjugated goat anti-rabbit IgG H\&L were obtained from Abcam (Tokyo, Japan). Horseradish peroxidase (HRP)conjugated anti-rabbit IgG, HRP-conjugated anti-mouse $\mathrm{IgG}$, polyvinylidene difluoride (PVDF) membrane, and ECL Prime Western Blotting Detection Kit were obtained from GE Healthcare Japan (Tokyo, Japan). Antibodies used for immunofluorescence staining were diluted with phosphate-buffered saline (PBS) containing $1 \%$ bovine serum albumin (BSA), and those used for western blotting were diluted with $20 \mathrm{mM}$ Tris- $\mathrm{HCl}$ buffer (pH 7.6) containing $137 \mathrm{mM} \mathrm{NaCl}$ and $0.1 \%$ Tween 20 .

Cell culture and DNA measurement. LM8 cells $\left(3.75 \times 10^{3}\right.$ cells $\left./ \mathrm{cm}^{2}\right)$ were seeded on a $35-\mathrm{mm}$ plate in culture medium, which contained $10 \%$ fetal bovine serum (FBS), 100 units/ml penicillin, and $100 \mu \mathrm{g} / \mathrm{ml}$ streptomycin in Dulbecco's modified Eagle's medium (DMEM). Twenty-four hours after seeding, the medium was replaced with culture medium containing bisphenol at different concentrations and changed every two days. Cells were incubated for 1-3 days, harvested in $0.3 \mathrm{ml}$ of lysis buffer (10 mM Tris, $0.1 \%$ Triton X-100, $\mathrm{pH} 7.5$ ), sonicated briefly in ice, and centrifuged at $13,200 \times \mathrm{g}$ for $10 \mathrm{~min}$ at $4^{\circ} \mathrm{C}$ to obtain the supernatant. The DNA content in the supernatant was measured fluorometrically by the method of Hinegardner (31).

For the trypan blue exclusion test, LM8 cells were seeded on a 2well chamber slide (Thermo Scientific Japan) in culture medium, and incubated for 3 days in culture medium with or without $80 \mu \mathrm{M}$ BPA as described above. Cells were washed twice with PBS, stained for 1 min with $0.2 \%$ trypan blue in PBS, washed three times with PBS, and mounted in glycergel (Dako Japan Inc.) for light microscopy analysis (magnification: $\times 20$ ).

Hematoxylin-eosin $(H \& E)$ staining and immunofluorescence staining. LM8 cells on a 2-well chamber slide were incubated for 3 days in culture medium with or without $80 \mu \mathrm{M}$ bisphenol as described above. For H\&E staining, cells were fixed in $70 \%$ ethanol for $30 \mathrm{~min}$, incubated in $100 \%$ ethanol for $10 \mathrm{~min}$, stained with $\mathrm{H} \& \mathrm{E}$, and mounted in glycergel for light microscopy analysis (magnification: $\times 20$ ). Six fields of the untreated cultures, seven of BPF-treated cultures, eight of BPE-treated cultures, 10 of BPA-treated cultures, and 10 of BPBtreated cultures were randomly photographed. The proportion of spindle-shaped cells was calculated by dividing the number of spindleshaped cells by the total number of cells (18-267 cells/field) in a field.

For the labeling of DNA with BrdU, cells were incubated with 30 $\mu \mathrm{M}$ BrdU during the last $2 \mathrm{~h}$ of the 3-day treatment period. Cells were then fixed in $70 \%$ ethanol for $30 \mathrm{~min}$, incubated in $100 \%$ ethanol for $10 \mathrm{~min}$, treated with $1.5 \mathrm{~N} \mathrm{HCl}$ for $30 \mathrm{~min}$, and treated with $0.5 \%$ Tween 20 for $5 \mathrm{~min}$. Thereafter, cells were incubated for $1 \mathrm{~h}$ with a mouse monoclonal antibody to BrdU (1:15 dilution), followed by 1$\mathrm{h}$ incubation with a FITC-labeled anti-mouse IgG (1:20 dilution) in the dark. Cells were subsequently mounted in fluorescence mounting medium (Dako Japan Inc) for fluorescence microscopy analysis (magnification: $\times 10$ ). Five fields of the untreated cultures, nine of BPF-treated cultures, eight of BPE-treated cultures, seven of BPAtreated cultures, and 14 of BPB-treated cultures were randomly photographed. The BrdU-labeling index was calculated by dividing the number of BrdU-positive cells by the total number of cells (31371 cells/field) in a field.

For immunofluorescence staining of CDC42, cells were fixed in $70 \%$ ethanol for $30 \mathrm{~min}$, and incubated in $100 \%$ ethanol for $10 \mathrm{~min}$. Cells were incubated overnight at $4^{\circ} \mathrm{C}$ with a rabbit polyclonal antibody to CDC42 $(5 \mu \mathrm{g} / \mathrm{ml})$, followed by $1-\mathrm{h}$ incubation with an Alexa Fluor ${ }^{\circledR} 488$-conjugated anti-rabbit $\operatorname{IgG}(2 \mu \mathrm{g} / \mathrm{ml})$ in the dark. Thereafter, cells were incubated for 5 min with $300 \mathrm{nM}$ DAPI in PBS, washed three times with PBS for 5 min in the dark, and mounted in fluorescence mounting medium for fluorescence microscopy analysis (magnification: $\times 40$ ).

Cell motility and invasion assay. Cell motility and invasion were assayed using inserts with either uncoated membranes (12 wells, 8 $\mu \mathrm{m}$ pore size; BD Biosciences, Franklin Lake, NJ) or matrigel-coated membranes ( 6 wells, $8 \mu \mathrm{m}$ pore size; BD Biosciences) in the invasion chambers as described previously (29). Briefly, the chambers were assembled using the inserts with membranes and DMEM containing $10 \%$ FBS as a chemoattractant in the lower compartment. LM8 cells, which had been treated with or without $80 \mu \mathrm{M}$ BPA for 3 days, were harvested by trypsinization, and suspended in FBS-free DMEM containing $0.1 \%$ BSA. The cell suspension $\left(2.5 \times 10^{5}\right.$ cells $/ \mathrm{ml}$ for motility assay or $5 \times 10^{5}$ cells $/ 2 \mathrm{ml}$ for invasion assay) was added to the inserts. The assembled chambers were incubated for $24 \mathrm{~h}$ (for motility assay) or $48 \mathrm{~h}$ (for invasion assay) at $37^{\circ} \mathrm{C}$. After removal of non-migrating cells on the upper surface of the membrane by wiping with a cotton swab, the cells on the bottom surface of the membrane were fixed with $100 \%$ ethanol for $30 \mathrm{~s}$ and stained with toluidine blue for $10 \mathrm{~min}$. The membrane was washed with ethanol and dried. The dye was dissolved with $10 \%$ acetic acid and quantitated by measuring the absorbance at $590 \mathrm{~nm}$.

Gelatin zymography and western blotting. For gelatin zymography, cells were incubated for 2 days in culture medium with or without 80 $\mu \mathrm{M}$ BPA, washed three times with PBS, and incubated for $1 \mathrm{~h}$ in FBS-free UltraCULTURE ${ }^{\text {TM }}$. The medium was then replaced with FBS-free UltraCULTURE ${ }^{\mathrm{TM}}$ with or without $80 \mu \mathrm{M}$ BPA. Cells were incubated for an additional $24 \mathrm{~h}$, harvested in $0.6 \mathrm{ml}$ of lysis buffer, 
sonicated briefly in ice, and centrifuged to obtain the supernatant. The media were filtered through $0.2-\mu \mathrm{m}$ filters. The same amount of protein in either the supernatant or the medium was resolved on sodium dodecyl sulfate-polyacrylamide gel electrophoresis (SDSPAGE, $7.5 \%$ acrylamide gel containing $0.1 \%$ gelatin) under nonreducing condition. The gels were incubated in $20 \mathrm{mM}$ Tris- $\mathrm{HCl}$ buffer ( $\mathrm{pH} 8.0$ ) containing $2.5 \%$ Triton $\mathrm{X}-100$ for $30 \mathrm{~min}$ at room temperature, incubated in $20 \mathrm{mM}$ Tris- $\mathrm{HCl}$ buffer ( $\mathrm{pH}$ 8.0) containing $1 \mu \mathrm{M} \mathrm{ZnCl}_{2}$ and $10 \mathrm{mM} \mathrm{CaCl}_{2}$ for $24 \mathrm{~h}$ at $37^{\circ} \mathrm{C}$, and stained with PAGE blue. Since matrix metalloproteinase 2 (MMP2) degrades gelatin, areas of enzyme activity appear as clear bands against a blue background. Relative densitometric units for this band were determined using the analysis software, Diversity Database ${ }^{\mathrm{TM}}$ (v. 1.1, Toyobo Co., Osaka, Japan).

For western blotting, cells were incubated for 3 days in culture medium with or without $80 \mu \mathrm{M} \mathrm{BPA}$, harvested in $0.4 \mathrm{ml}$ of lysis buffer, sonicated briefly in ice, and centrifuged to obtain the supernatant. The same amount of protein in the supernatant was separated by SDS-PAGE (10\% acrylamide gel), and the separated proteins were transferred to a PVDF membrane. The membrane was incubated for $1 \mathrm{~h}$ with either a rabbit polyclonal antibody to CDC42 $(1 \mu \mathrm{g} / \mathrm{ml})$ or a mouse monoclonal antibody to GAPDH $(1 \mu \mathrm{g} / \mathrm{ml})$, followed by 1 -h incubation with either a HRP-conjugated anti-rabbit IgG (1:25,000 dilution) or a HRP-conjugated anti-mouse IgG (1:25,000 dilution). Blots were visualized using the ECL Prime Western Blotting Detection Kit and data were analyzed using AE9300H Ez-Capture MG (ATTO Co., Tokyo, Japan). Relative densitometric units for each blot were determined as described above.

Statistical analyses. Significant differences among multiple independent groups were evaluated using one-way analysis of variance (ANOVA), and subsequent comparisons were performed using the Scheffe test for an equal number of samples and the TukeyKramer test for an unequal number of samples. Significant differences between two independent groups were analyzed using Student's $t$-test. For all statistical analyses, the criterion for significance was $p<0.05$. All data values are expressed as the mean \pm standard deviation (SD).

\section{Results}

Effect of BPA on cell proliferation. LM8 cells were treated for 3 days with BPA and the DNA content of the cultures was measured to examine the effect of BPA on cell proliferation. The untreated cultures, in which BPA was absent during the 3-day treatment period, contained 51.4 $\mu \mathrm{g}$ DNA/35 mm plate. BPA treatment caused a decrease in the DNA content of the culture in a dose-dependent manner. BPA at concentrations of 40,80 , and $120 \mu \mathrm{M}$ reduced the DNA content by $20 \%$ $(p<0.01), 52 \%(p<0.01)$, and $75 \% \quad(p<0.01)$, respectively (Figure 1A).

BPB also caused a decrease in the DNA content of the cultures in a similar dose-dependent manner to BPA (Table I). In the presence of $120 \mu \mathrm{M}$ BPB, the DNA content of the BPBtreated cultures on day 3 was identical to that of the cultures on day 0 , indicating that LM8 cells in culture medium containing $120 \mu \mathrm{M}$ BPB did not grow during the 3-day treatment period. Therefore, we performed the subsequent experiments using bisphenol at $80 \mu \mathrm{M}$.
Table I. Effect of high concentrations of bisphenol A (BPA) and bisphenol $B(B P B)$ on cell proliferation. LM8 cells were seeded on a 35-mm plate in culture medium. In one group, $24 \mathrm{~h}$ after seeding, cells were harvested to measure the DNA content of the cultures (day 0). In another group, $24 \mathrm{~h}$ after seeding, the medium was replaced with culture medium containing either 80 or $120 \mu \mathrm{M}$ of bisphenol. Cells were treated for 3 days and then harvested to measure the DNA content of the cultures (day 3). The results are expressed as the mean $\pm S D$ for three or four plates.

\begin{tabular}{lcccc}
\hline & & $\begin{array}{c}\text { Concentration } \\
(\mu \mathrm{M})\end{array}$ & \multicolumn{2}{c}{ DNA content $(\mu \mathrm{g} /$ plate $)$} \\
\cline { 4 - 5 } & & & Day 0 & Day 3 \\
\hline \multirow{2}{*}{ No additive } & $(\mathrm{n}=4)$ & & $2.62 \pm 0.23$ & $19.3 \pm 0.80^{*}$ \\
BPA & $(\mathrm{n}=4)$ & 80 & - & $9.71 \pm 0.39^{*} \ddagger$ \\
& $(\mathrm{n}=3)$ & 120 & - & $6.00 \pm 0.51^{* \dagger}$ \\
BPB & $(n=4)$ & 80 & - & $5.58 \pm 0.53^{* \dagger}$ \\
& $(n=4)$ & 120 & - & $2.98 \pm 0.18^{\ddagger}$ \\
\hline
\end{tabular}

$* p<0.01$ versus untreated cultures on day $0, \ddagger p<0.01$ versus untreated cultures on day 3 .

LM8 cells were treated for 3 days with or without $80 \mu \mathrm{M}$ BPA, and the DNA content of the cultures was measured at daily intervals (Figure 1B). In both the untreated and BPAtreated cultures, the DNA content increased during the 3-day treatment period. On day 1 , there was no difference in the DNA content between the two cultures. On days 2 and 3, the DNA content of the BPA-treated cultures was $36 \%(p<0.01)$ and $54 \%(p<0.01)$ lower, respectively, than that of the untreated cultures. Thus, LM8 cells grew at a lower rate in the BPA-treated cultures than in the untreated cultures.

To examine the effect of $80 \mu \mathrm{M}$ BPA on cell viability, the trypan blue exclusion test was performed. In both the untreated and BPA-treated cultures, cells that attached to the bottom of the plates excluded trypan blue (Figure 1C), indicating that they were viable. Moreover, in both cultures LM8 cells did not detach from the bottom of the plates during the 3-day treatment period.

Effect of bisphenols with different substituents on cell proliferation. BPA, BPB, BPE, and BPF are diphenylalkanes with alkyl substituents of different lengths on the central carbon atom between the two phenolic rings. The order of the length of the substituent is $\mathrm{BPB}>\mathrm{BPA}>\mathrm{BPE}>\mathrm{BPF}$ (Figure $2 \mathrm{~A}$ ). LM8 cells were treated for 3 days with or without $80 \mu \mathrm{M}$ bisphenol, and the DNA content of the cultures was measured. The DNA content was $42 \%$ lower $(p<0.01)$ in the BPF-treated cultures, $33 \%$ lower $(p<0.01)$ in the BPE-treated cultures, $50 \%$ lower $(p<0.01)$ in the BPA-treated cultures, and $73 \%$ lower $(p<0.01)$ in the BPB-treated cultures, compared with the untreated cultures (Figure 2B). The difference in the DNA content between the BPF-treated and BPE-treated cultures was not significant. Thus, the order of the potential for reducing the DNA content was $\mathrm{BPB}>\mathrm{BPA}>\mathrm{BPF} \geq \mathrm{BPE}$. 

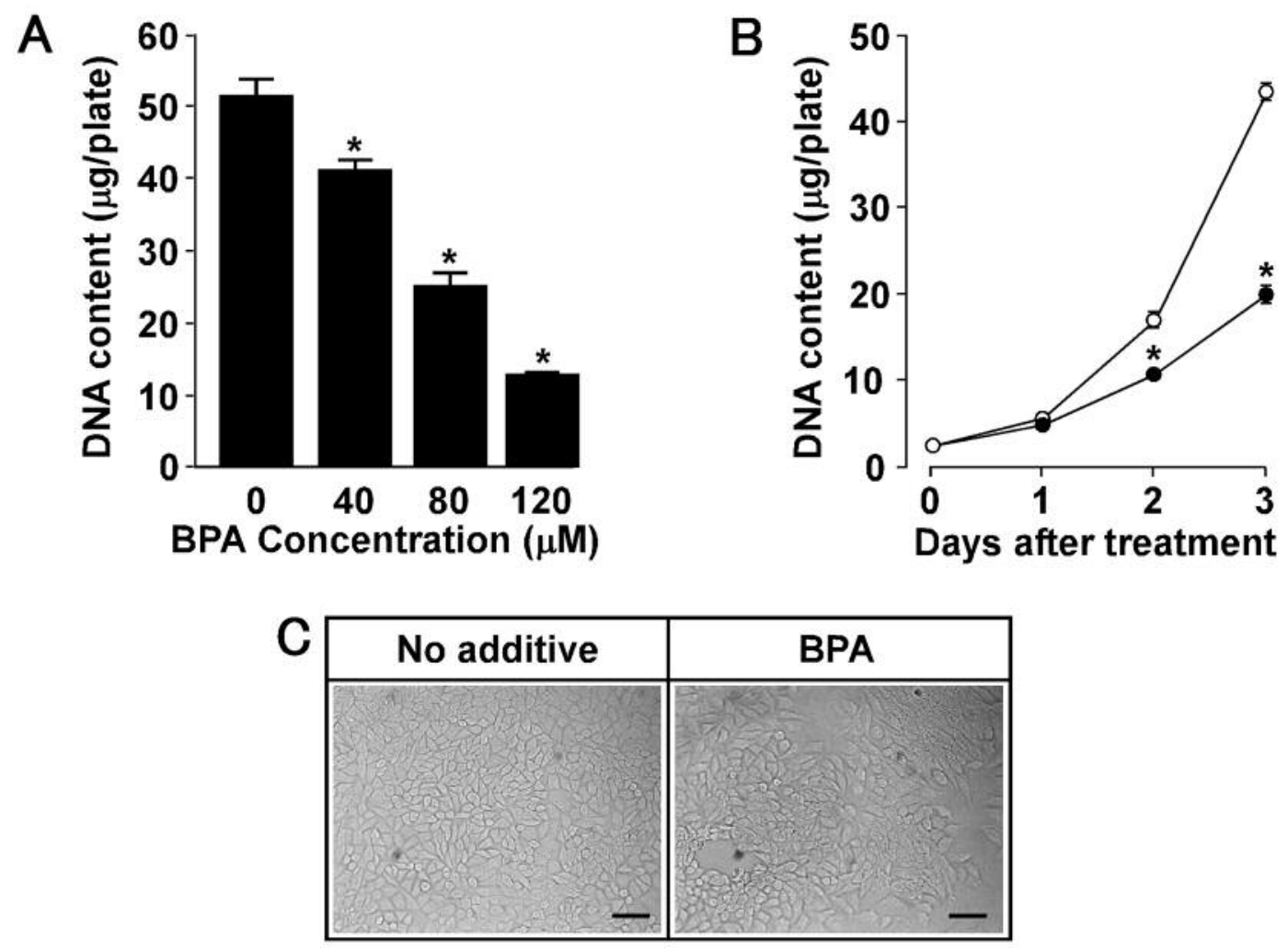

Figure 1. Effect of bisphenol A (BPA) on cell proliferation. A: LM8 cells were treated for 3 days with BPA at the indicated concentrations, and the $D N A$ content of the cultures was measured. The results are expressed as the mean \pm SD for four plates. B: LM8 cells were treated with (filled circle) or without (open circle) $80 \mu \mathrm{M} \mathrm{BPA}$, and the DNA content of the cultures was measured at the indicated intervals. The results are expressed as the mean $\pm S D$ for four plates. ${ }^{*} p<0.01$ Compared to the untreated cultures. $C$ : The trypan blue exclusion test was performed using cultures treated for 3 days with (the right panel) or without (the left panel) $80 \mu \mathrm{M}$ BPA. Scale bar: $50 \mu \mathrm{m}$.

Next, we examined the effect of bisphenols with substituents on the hydroxyl groups in the para position of the phenolic rings on the DNA content of the cultures. BPDA, BPDM, and BPBCF are ester derivatives of BPA (Figure 3A). The DNA content was $44 \%$ lower $(p<0.01)$ in the BPA-treated cultures, $48 \%$ lower $(p<0.01)$ in the BPDA-treated cultures, $85 \%$ lower $(p<0.01)$ in the BPDM-treated cultures, and $72 \%$ lower $(p<0.01)$ in the BPBCF-treated cultures, compared to the untreated cultures (Figure 3B). BPDGE and BPDAA are ether derivatives of BPA (Figure 3A). The DNA content of the BPDGE-treated cultures was $28 \%$ lower $(p<0.01)$ than that of the untreated cultures, but $23 \%$ higher $(p<0.01)$ than that of the BPA-treated cultures (Figure 3C). The DNA content of the BPDAA-treated cultures did not differ from that of the untreated cultures.

Effect of bisphenols on DNA replication. LM8 cells were incubated with BrdU during the last $2 \mathrm{~h}$ of the 3-day treatment period to examine the effect of bisphenols on DNA replication. The total number of cells was 1,069 in five fields for the untreated cultures, 1,012 in nine fields for the BPF- treated cultures, 1,110 in eight fields for the BPE-treated cultures, 1,059 in seven fields for the BPA-treated cultures, and 868 in 14 fields for the BPB-treated cultures. In all cultures, we observed positive BrdU immunofluorescence staining in the nucleus (Figure 4, right panels). The BrdUlabeling index of the untreated cultures was $61.6 \pm 6.8 \%$ (Figure 4B), indicating that $61.6 \%$ of cells in the cultures synthesized DNA. The BrdU-labeling index $(52.4 \pm 20.8 \%)$ of the BPF-treated cultures was lower than that of the untreated cultures, but this difference was not significant (Figure 4D). The BrdU-labeling indices of the BPE-treated (Figure 4F) and BPA-treated cultures (Figure $4 \mathrm{H}$ ) were significantly lower than those of the untreated cultures, indicating that both BPE and BPA inhibited DNA replication. The BrdU-labeling index of the BPB-treated cultures was $18.2 \pm 11.4 \%$ (Figure $4 \mathrm{~J}$ ). The nuclei of some binucleated cells in the BPB-treated cultures were BrdU-positive (Figure 4I and J, arrowhead).

Effect of bisphenols on cell morphology. Ethanol-fixed LM8 cells were stained with $H \& E$ to examine the effect of bisphenols on cell morphology. The total number of cells was 

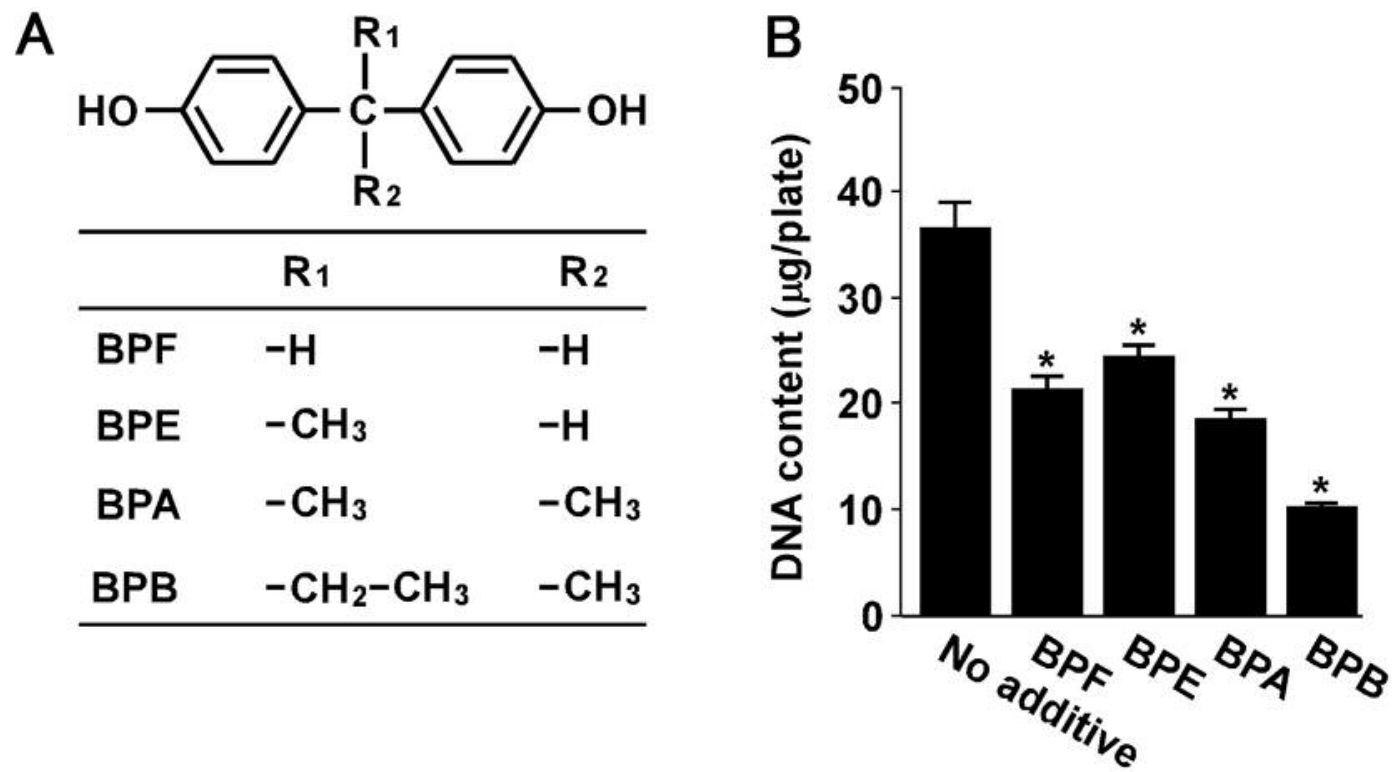

Figure 2. Effect of bisphenols with alkyl substituents of different lengths at the central carbon atom on cell proliferation. A: Structure of bisphenols with alkyl substituents of different lengths on the central carbon atom between the two phenolic rings. B: LM8 cells were treated for 3 days with or without $80 \mu \mathrm{M}$ bisphenol, and the DNA content of the cultures was measured. The results are expressed as the mean $\pm S D$ for four plates. * $<<0.01$ Compared to the untreated cultures.

765 in six fields for the untreated cultures, 799 in seven fields for the BPF-treated cultures, 1,054 in eight fields for the BPEtreated cultures, 856 in 10 fields for the BPA-treated cultures, and 288 in 10 fields for the BPB-treated cultures. The cultures contained two morphologically different types of LM8 cells. The first type of cell morphology was cuboidal with multiple filopodia on the cell surface (Figure 5A-i, inset), while the second was spindle-shaped cells with a smooth and spreading surface (Figure 5A-iv, inset). In the untreated cultures, the majority of cells $(93.5 \pm 3.5 \%)$ were cuboidal (Figure $5 \mathrm{~A}-\mathrm{i})$ and the remaining $(6.5 \pm 3.5 \%)$ were spindle-shaped (Figure $5 \mathrm{~B})$. The presence of BPF, BPE, and BPA significantly increased the proportion of spindle-shaped cells (Figure 5A-ii, -iii and iv, and B). In the BPB-treated cultures, the majority of cells $(91.0 \pm 8.3 \%)$ were cuboidal (Figure 5A-v, and B).

We observed binucleated cells in all of the cultures. The ratio of binucleated cells to total cells in the culture was $0.9 \%$ in untreated cultures, $1.1 \%$ in BPA-treated cultures, $0.5 \%$ in BPE-treated cultures, and $1.3 \%$ in BPF-treated cultures. The BPB-treated cultures contained binucleated and multinucleated cells, which had a larger cytoplasm than mononucleated cells (Figure $5 \mathrm{~A}-\mathrm{v}$, the inset). The ratio of cells having more than two nuclei to total cells was $42.4 \%$.

Effect of BPA on cell motility and CDC42 expression. Cell motility was assayed using inserts with uncoated membranes in invasion chambers. Migrating cells on the bottom surface of the membranes were fixed in ethanol, and stained with toluidine blue. The absorbance of the dye extracted from BPAtreated cells was $54.9 \%(p<0.01)$ of that of the dye extracted from untreated cells (Figure 6A), indicating that the number of migrating BPA-treated cells on the bottom surface was smaller than that of migrating untreated cells.

We performed immunofluorescence staining of CDC42, which belongs to the Rho family of Ras-like GTPases (32) and is involved in the formation of filopodia $(33,34)$, in order to determine the effect of BPA on CDC42 expression in LM8 cells (Figure 6B-i and -iii). We counterstained the nucleus with DAPI (Figure 6B-ii and -iv). Positive CDC42 immunofluorescence staining was observed in both the untreated and BPA-treated cultures; however, the intensity of the fluorescence signal was weaker in the BPA-treated cultures than in the untreated cultures. This finding suggests that BPA may inhibit CDC42 expression in LM8 cells. To verify this, the cellular level of CDC42 was determined by western blotting. The intensity of the band corresponding to CDC42 was weaker $(p<0.01)$ in the BPA-treated cultures than in the untreated cultures (Figure 6C), indicating that BPA reduced the cellular level of CDC42.

Effect of BPA on MMP2 and cell invasion. Since MMP2 plays a pivotal role in cell invasion (35), the effect of BPA on MMP2 activity was examined by gelatin zymography (Figure 7A). The activity of MMP2 in cells was lower $(p<0.05)$ in the BPA-treated cultures than in the untreated cultures. The activity of MMP2 secreted into the medium during the last 

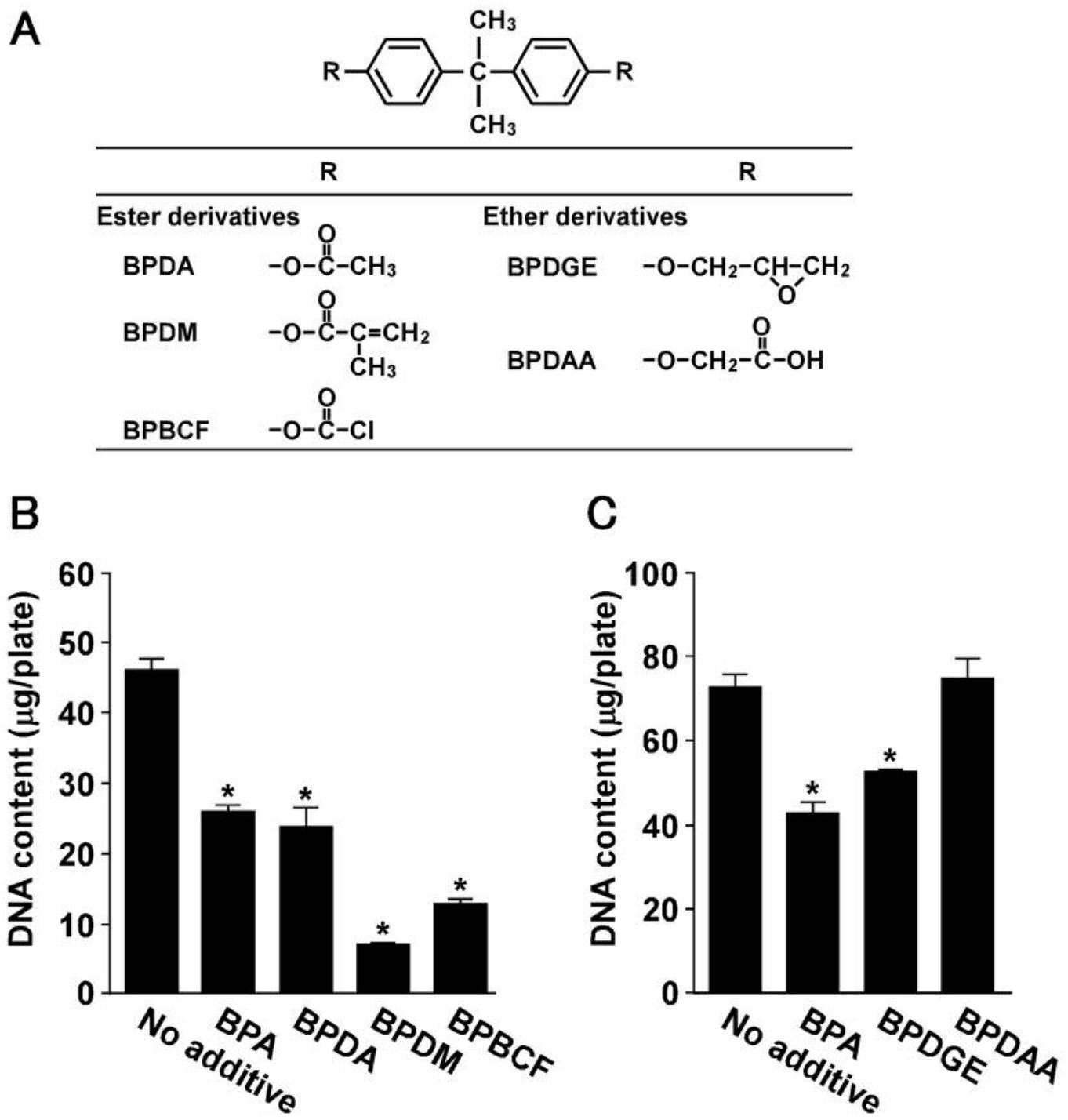

Figure 3. Effect of bisphenol A (BPA) with different substituents on the hydroxyl groups in the para position of the phenolic rings on cell proliferation. A: Structure of BPA with different substituents on the hydroxyl groups in the para position of the phenolic rings. B and C: LM8 cells were treated for 3 days with or without either $80 \mu \mathrm{MBPA}$ ester derivative $(B)$ or $80 \mu \mathrm{MBPA}$ ether derivative $(C)$, and the DNA content of the cultures was measured. The results are expressed as the mean $\pm S D$ for four plates. ${ }^{*} p<0.01$ Compared to the untreated cultures.

$24 \mathrm{~h}$ of the 3-day treatment period also was lower $(p<0.05)$ in the BPA-treated cultures than in the untreated cultures.

Cell invasion was assayed using inserts with matrigelcoated membranes in invasion chambers. The absorbance of the dye extracted from BPA-treated cells was $85.9 \%$ of that of the dye extracted from untreated cells, but this difference was not significant (Figure 7B).

\section{Discussion}

In this study, we first examined the effect of BPA on the proliferation of LM8 cells. By measuring the DNA content, we found that the presence of BPA in cultures caused a dosedependent decrease in the DNA content (Figure 1A). Of course, there is concern that the BPA-induced decrease in the DNA content of the cultures could result from a cytotoxic effect of BPA toward LM8 cells because $100 \mu \mathrm{M}$ BPA has been reported to be cytotoxic toward MCF-7 cells (17). However, this does not appear to be the case because LM8 cells in both untreated and BPA-treated cultures were viable (Figure 1C) and did not detach from the bottom of the plates during the 3-day treatment period. Moreover, LM8 cells grew even in cultures containing $120 \mu \mathrm{M}$ BPA (Table I). The results of BrdU incorporation into DNA revealed that $61.6 \%$ of cells 


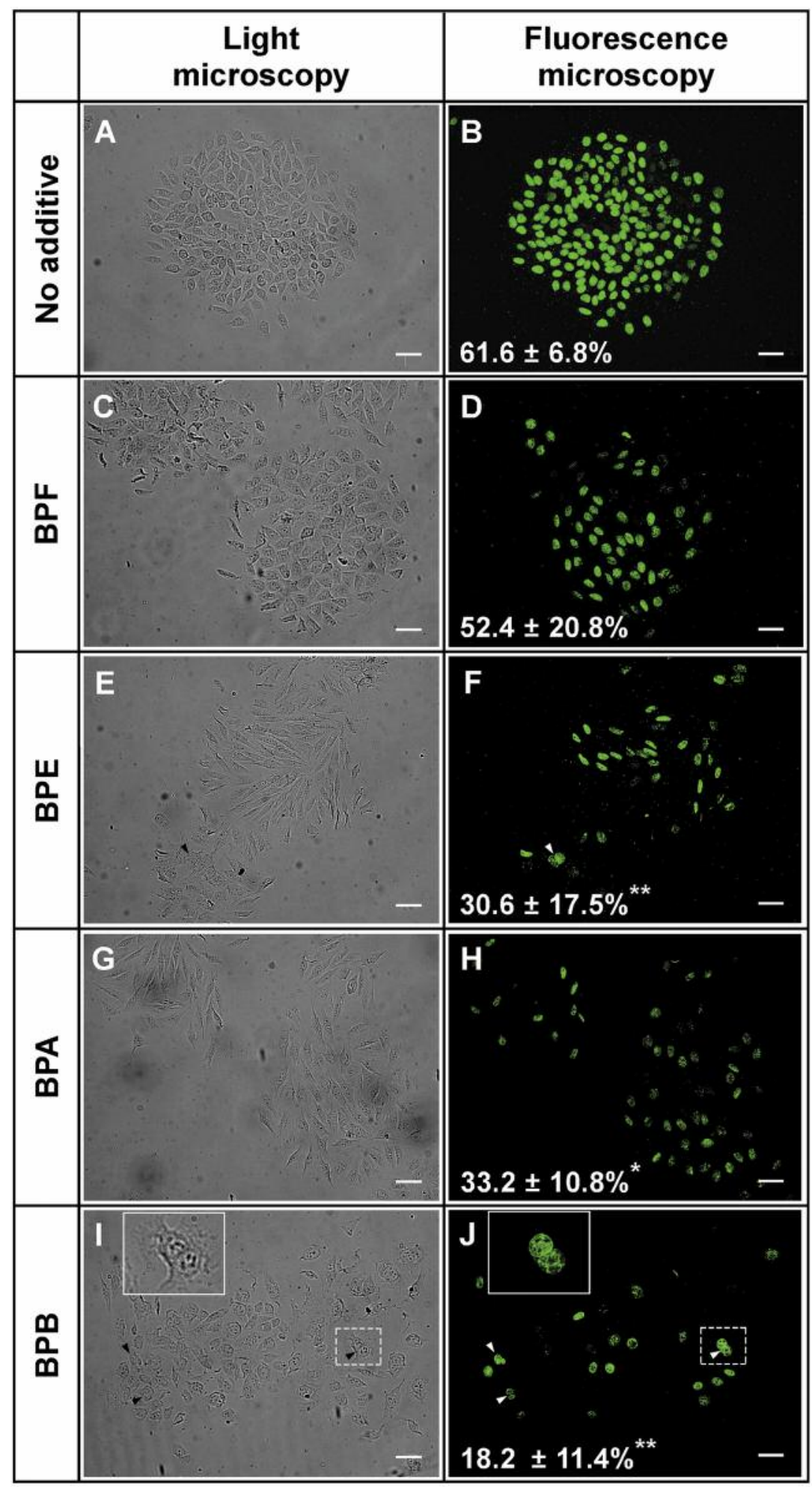

Figure 4. Effect of bisphenols (BPs) on DNA replication. LM8 cells were treated for 3 days without $(A, B)$ or with either $80 \mu M B P F(C, D), 80 \mu M$ $B P E(E, F), 80 \mu M B P A(G, H)$, or $80 \mu M B P B(I, J)$. Immunofluorescence staining of BrdU incorporated into DNA was performed. Light and fluorescence images show the same field of view. Arrowhead indicates BrdU-positive nuclei in a binucleated cell. The inset (solid line) in panels $(I)$ and $(J)$ shows a magnified image of the areas enclosed by the dotted line. The values shown in the photographs represent the BrdU-labeling index. The results are expressed as the mean $\pm S D$ for 5, 9, 8, 7, and 14 fields of the untreated, BPF-, BPE-, BPA- and BPB-treated cultures, respectively. Scale bar: $100 \mu m .{ }^{*} p<0.05$ and ${ }^{* *} p<0.01$ Compared to the untreated cultures. 

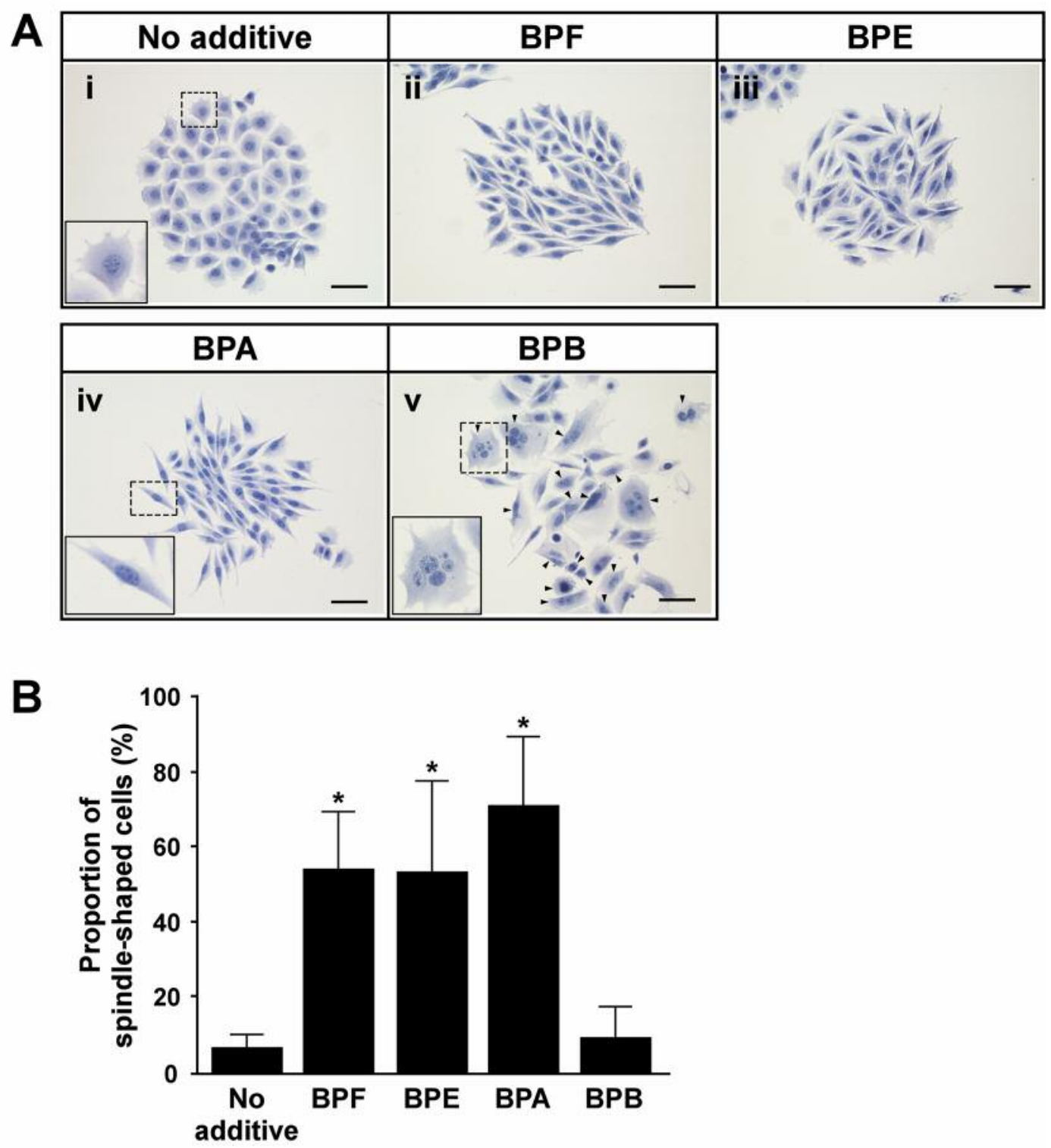

Figure 5. Effect of bisphenols (BPs) on cell morphology. A: LM8 cells were treated for 3 days without (i) or with either $80 \mu M$ BPF (ii), $80 \mu M$ $B P E$ (iii), $80 \mu M$ BPA (iv), or $80 \mu M B P B(v)$. Cells were then fixed in ethanol and stained with hematoxylin-eosin. Arrowheads in panel (v) indicate either a binucleated or multinucleated cell. The inset (solid line) in panels (i), (iv), and (v) shows the magnified image of the areas enclosed by the dotted line. Scale bar: $50 \mu \mathrm{m}$. B: The proportion of spindle-shaped cells is shown. The results are expressed as the mean $\pm S D$ for 6, 7, 8, 10, and 10 fields of the untreated, BPF-, BPE-, BPA- and BPB-treated cultures, respectively. ${ }^{*} p<0.01$ Compared to the untreated cultures.

in the untreated cultures synthesized DNA (Figure 4A), while in the BPA-treated cultures, only $33.2 \%$ of cells synthesized it (Figure 4H). Thus, the number of cells that entered the $\mathrm{S}$ phase of the cell cycle was smaller in the BPA-treated cultures than in the untreated cultures. Based on these findings, we concluded that BPA inhibits DNA synthesis by arresting LM8 cells in $G_{1} / G_{0}$ phase and inhibits cell proliferation without affecting cell viability. The findings of others that BPA promotes the growth of MCF-7 cells $(4,15-17)$ and SK-N-SH cells (18) indicate that BPA promotes entry of these cells into the $S$ phase. Thus, the regulation of cell cycle by BPA appears to depend on the cell type.

In the BPB-treated cultures, we observed binucleated and multinucleated cells with a larger cytoplasm than mononucleated cells (Figure 5A-v). The nuclei in some binucleated cells were BrdU-positive and were partially in contact with each other (Figure 4J, inset). Moreover, multinucleated cells with more than three BrdU-positive nuclei 

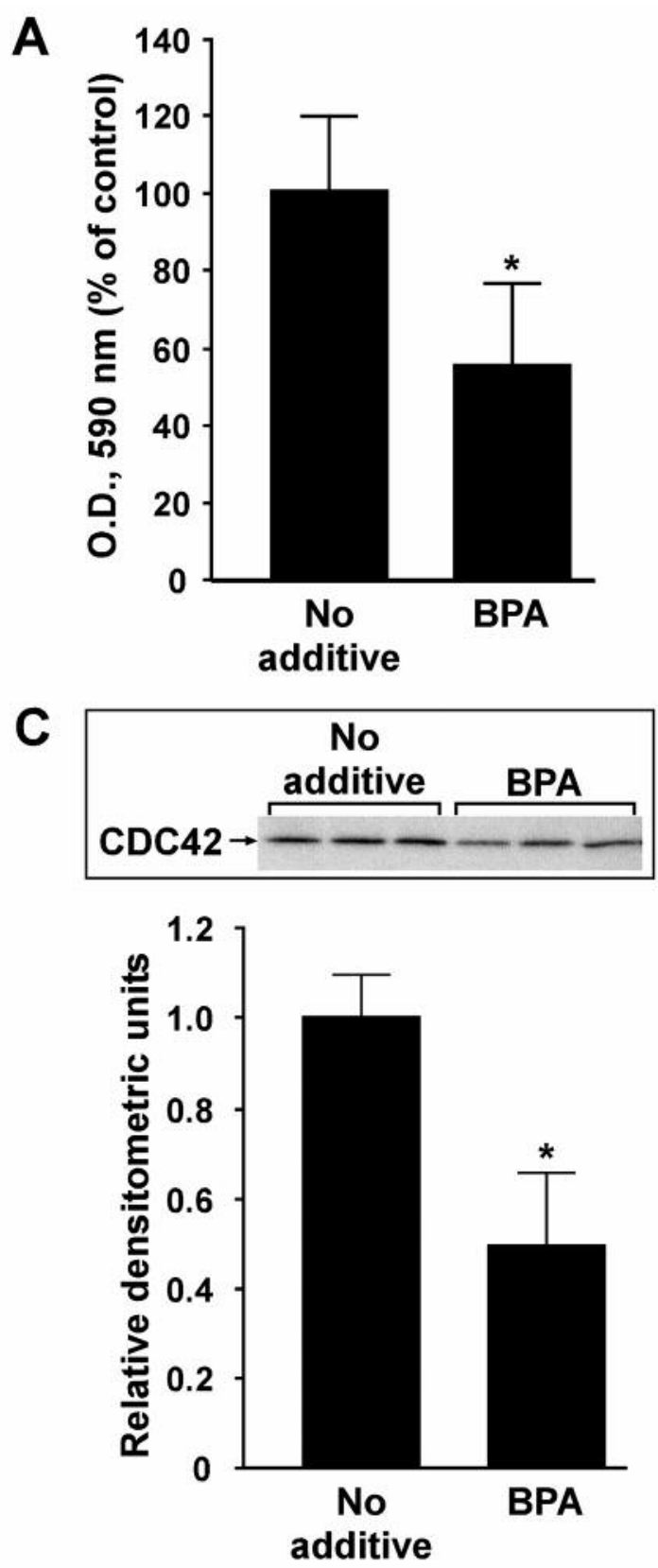

B
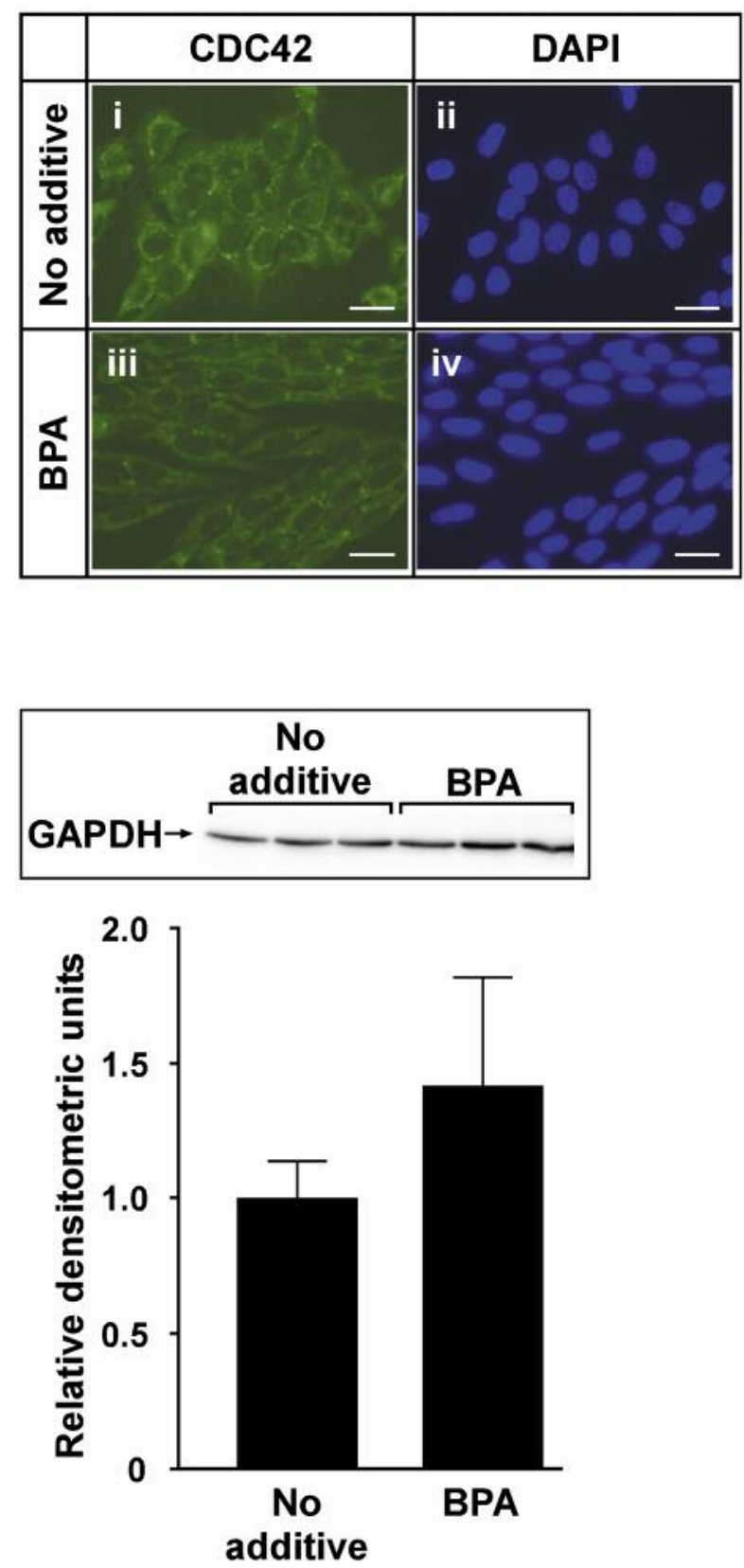

Figure 6. Effects of bisphenol A (BPA) on cell motility and cell division cycle 42 (CDC42) expression. A: Cell motility assay was performed using inserts with uncoated membranes in invasion chambers. The results are expressed as the mean $\pm S D$ for 18 inserts. B: Immunofluorescence staining of CDC42 was performed ( $i$, iii). The nuclei were counterstained with 4',6-diamidino-2-phenylindole (DAPI) (ii, iv). The left and right fluorescence micrographs show the same field of view. Scale bar: $50 \mu \mathrm{m}$. C: The cellular level of CDC42 was determined by western blotting. Glyceraldehyde3-phosphate dehydrogenase (GAPDH) was used as internal control. The experiments were performed using samples obtained from three independent plates for each treatment. The results are expressed as the mean $\pm S D$ for three plates. ${ }^{*} p<0.01$ Compared to the untreated cultures.

were also observed in the BPB-treated cultures (data not shown). These findings suggest that binucleated and multinucleated cells in the BPB-treated cultures may be formed by direct nuclear division without cytokinesis in $\mathrm{G}_{2^{-}}$ phase arrested cells. Kusuzaki et al. observed binucleated cells in acridine orange-treated giant cell tumor of the bone. They reported that binucleated cells in this tumor may be formed from $\mathrm{G}_{2}$-phase arrested cells by amitotic nuclear division, but not by mitosis without cytokinesis, or by cell fusion (36). It has also been reported that the binucleation observed in 

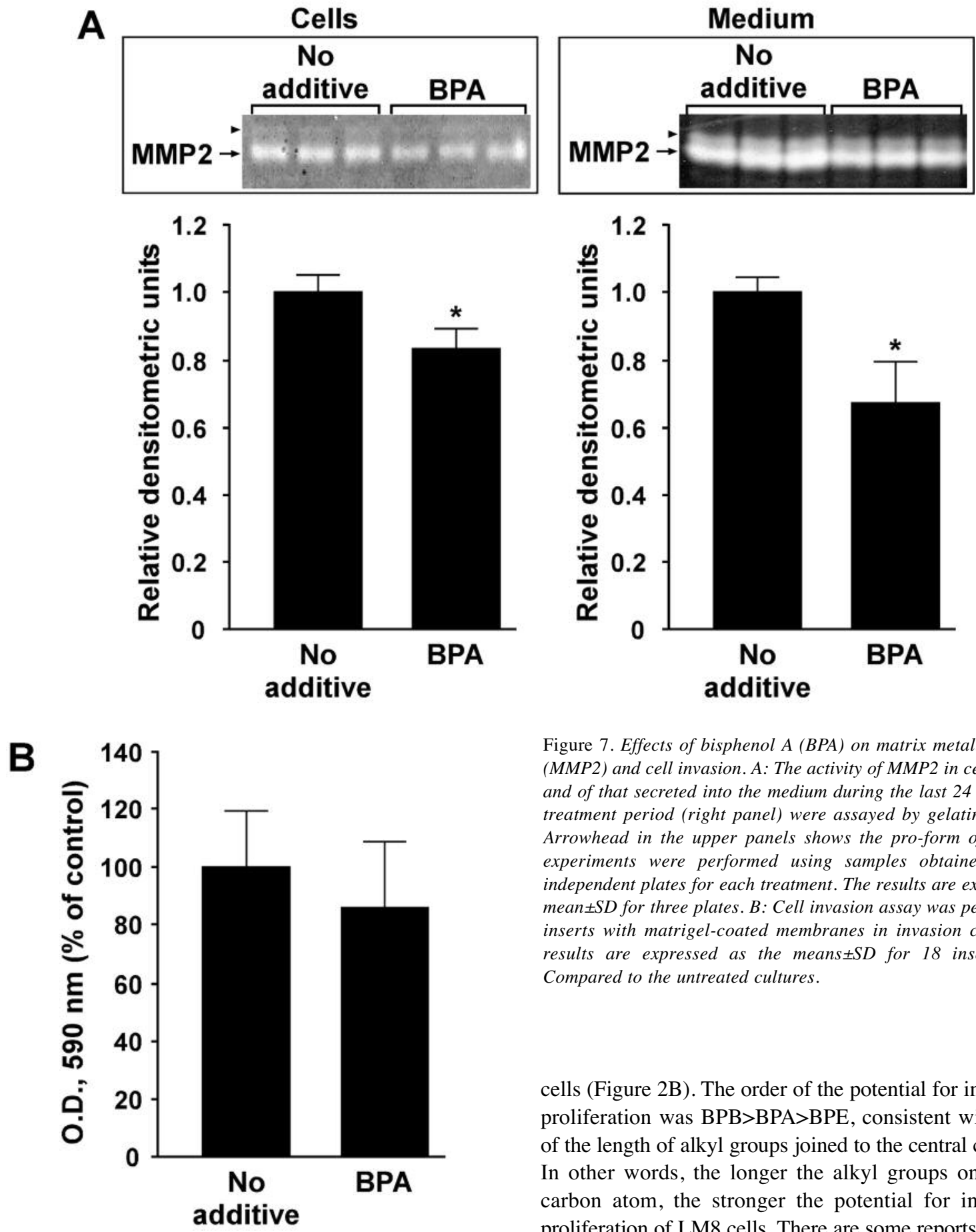

Figure 7. Effects of bisphenol A (BPA) on matrix metalloproteinase 2 (MMP2) and cell invasion. A: The activity of MMP2 in cells (left panel) and of that secreted into the medium during the last $24 \mathrm{~h}$ of the 3-day treatment period (right panel) were assayed by gelatin zymography. Arrowhead in the upper panels shows the pro-form of MMP2. The experiments were performed using samples obtained from three independent plates for each treatment. The results are expressed as the mean $\pm S D$ for three plates. B: Cell invasion assay was performed using inserts with matrigel-coated membranes in invasion chambers. The results are expressed as the means $\pm S D$ for 18 inserts. ${ }^{*} p<0.05$ Compared to the untreated cultures.

Drosophila male accessory gland cells results from undergoing mitosis without cytokinesis (37).

BPE, BPA, and BPB are diphenylalkanes with one hydrogen atom and one methyl group, two methyl groups, and one methyl group and one ethyl group, respectively, on the central carbon atom between the two phenolic rings (Figure 2A). These bisphenols all inhibited the proliferation of LM8

cells (Figure 2B). The order of the potential for inhibiting cell proliferation was $\mathrm{BPB}>\mathrm{BPA}>\mathrm{BPE}$, consistent with the order of the length of alkyl groups joined to the central carbon atom. In other words, the longer the alkyl groups on the central carbon atom, the stronger the potential for inhibiting the proliferation of LM8 cells. There are some reports on the same order of BPA-induced actions. For example, the order of the potential for inhibiting adiponectin production in 3T3-L1 adipocytes was found to be BPB $>$ BPA $>$ BPE (38). Perez et al. reported that the estrogenicity of BPA derivatives is influenced not only by the length of the substituents on the central carbon atom but also by their nature (16).

Three ester derivatives of BPA tested in this study all inhibited the proliferation of LM8 cells. The order of the 
potential for inhibiting cell proliferation was BPDM> $\mathrm{BPBCF}>\mathrm{BPDA}=\mathrm{BPA}$ (Figure 3B). The ether derivative BPDGE, but not BPDAA, also inhibited cell proliferation; however, the potential of BPDGE to inhibit cell proliferation was lower than that of BPA (Figure 3C). Thus, the potential of the ester derivatives to inhibit the proliferation of LM8 cells was stronger than that of the ether derivatives. The relative proliferative potency of MCF-7 cells has also been reported to be higher in the presence of ester derivatives (BPDM, $\mathrm{BPBCF}$ ) than of the ether derivative (BPDGE) (16).

Tumor metastasis involves multiple steps, including cell motility and invasion, intravasation into blood, and extravasation into distant organs. LM8 cells possess a higher number of filopodia per cell $(27,39)$ and exhibit higher motile potential, compared with Dunn cells (39). Thus cell motility is associated with the formation of filopodia on the surface of cells. BPA induced a change in morphology from cuboidal with multiple filopodia on the cell surface to spindle-shaped with a smooth cell surface (Figure 5B), indicating that BPA inhibited the formation of filopodia on the surface of LM8 cells. This finding suggests that LM8 cells in BPA-treated cultures may be less motile than those in untreated cultures. This was confirmed by the results of the cell motility assay (Figure 6A), which was performed using inserts with uncoated membranes in invasion chambers. These findings raise the question of whether BPA affects CDC42 expression in LM8 cells because CDC42 promotes filopodia formation (33, 34, $40)$ and enhances cell motility $(39,40)$. To explore this, we performed immunofluorescence staining and western blotting of CDC42. As shown in Figure 6B and C, BPA inhibited the expression of $\mathrm{CDC} 42$ in LM8 cells. Taken together, the present findings indicate that BPA inhibited the formation of filopodia on the cell surface and reduced cell motile potential by inhibiting CDC42 expression in LM8 cells.

The critical event for tumor invasion and metastasis is the destruction of the extracellular matrix (ECM). MMPs degrade ECM macromolecules in the basement membranes and other interstitial connective tissues $(35,41)$. Invasive tumors exhibit high levels of MMPs $(27,35)$. LM8 cells have been reported to exhibit higher MMP2 activity and higher invasive potential than Dunn cells (27). The results of gelatin zymography revealed that BPA reduced the expression and secretion of MMP2 (Figure 7A). However, a significant difference in cell invasion between untreated and BPA-treated cells was not observed (Figure 7B). Therefore, BPA may have a minimal effect on intravasation of LM8 cells into blood and their extravasation into distant organs.

In conclusion, BPA inhibited DNA replication and cell proliferation in cultures of LM8 cells. BPA inhibited filopodia formation on the cell surface and reduced the motile potential by inhibiting CDC42 expression in LM8 cells. BPA reduced the expression and secretion of MMP2. Seven out of eight bisphenol derivatives tested in this study possessed the ability to inhibit the proliferation of LM8 cells. Herein, we propose that BPA and its derivatives may have potential as novel anti-proliferative and anti-metastatic agents for the treatment of osteosarcoma.

\section{Acknowledgements}

This work was supported and funded, in part, by a grant (Kyouiku Kenkyu Joseihi) from Ehime Prefectural University of Health Sciences Iyo-gun, Ehima, Japan (H. Masuno).

\section{References}

1 Brede C, Fjeldal P, Skjevrak I and Herikstad H: Increased migration levels of bisphenol A from polycarbonate baby bottles after dishwashing, boiling and brushing. Food Addit Contam 20: 684-689, 2003.

2 Welshons WV, Nagel SC and vom Saal FS: Large effects of small exposures. III. Endocrine mechanisms mediating effects of bisphenol A at levels of human exposure. Endocrinology 147: S56-S69, 2006

3 Brotons JA, Olea-Serrano FF, Villalobos M, Pedraza V and Olea $\mathrm{N}$ : Xenoestrogens released from lacquer coatings in food cans. Environ Health Perspect 103: 608-612, 1995.

4 Olea N, Pulgar R, Perez P, Olea-Serrano FF, Rivas A, NovilloFertrell A, Pedraza V, Soto AM and Sonnenschein C: Estrogenicity of resin-based composites and sealants used in dentistry. Environ Health Perspect 104: 298-305, 1996.

5 Jiang M, Zhang JM, Mei SR, Shi Y, Zou LJ, Zhu YX, Dai K and $\mathrm{Lu}$ B: Direct enrichment and high performance liquid chromatography analysis of ultra-trace bisphenol A in water samples with narrowly dispersible bisphenol A imprinted polymeric microspheres column. J Chromatogr A 1110: 27-34, 2006.

6 Inoue K, Kato K, Yoshimura Y, Makino T and Nakazawa H: Determination of bisphenol A in human serum by high-performance liquid chromatography with multi-electrode electrochemical detection. J Chromatogr B Biomed Sci Appl 749: 17-23, 2000.

7 Takeuchi T, Tsutsumi O, Ikezaki Y, Takai Y and Taketani Y: Positive relationship between androgen and the endocrine disruptor, bisphenol A, in normal women and women with ovarian dysfunction. Endocr J 51: 165-169, 2004.

8 Howdeshell KL, Hotchkiss AK, Thayer KA, Vandenbergh JG and vom Saal FS: Exposure to bisphenol A advances puberty. Nature 401: 763-764, 1999.

9 Kato H, Ota T, Furuhashi T, Ohta $\mathrm{Y}$ and Iguchi T: Changes in reproductive organs of female rats treated with bisphenol A during the neonatal period. Reprod Toxicol 17: 283-288, 2003.

10 Miyawaki J, Sakayama K, Kato H, Yamamoto H and Masuno H: Perinatal and postnatal exposure to bisphenol A increases adipose tissue mass and serum cholesterol level in mice. $\mathrm{J}$ Atheroscler Thromb 14: 245-252, 2007.

11 Papaconstantinou AD, Umbreit TH, Fisher BR, Goering PL, Lappas NT and Brown KM: Bisphenol A-induced increase in uterine weight and alterations in uterine morphology in overiectomized $\mathrm{B} 6 \mathrm{C} 3 \mathrm{~F} 1$ mice: role of the estrogen receptor. Toxicol Sci 56: 332-339, 2000.

12 Rubin BS, Murray MK, Damassa DA, King JC and Soto AM: Perinatal exposure to low doses of bisphenol A affects body weight, pattern of estrous cyclicity and plasma LH levels. Environ Health Perspect 109: 675-680, 2001. 
13 Rancière F, Lyons JG, Loh VHY, Botton J, Galloway T, Wang T, Shaw JE and Magliano D: Bisphenol A and the risk of cardiometabolic disorders: a systemastic review with meta-analysis of the epidemiological evidence. Environ Health 14: 46, 2015.

14 vom Saal FS and MyersJP: Bisphenol A and risk of metabolic disorders. JAMA 300: 1353-1355, 2008.

15 Krishman AV, Stathis P, Permuth S, Tokes L and Feldman D: Bisphenol A: An estrogenic substance is released from polycarbonate flasks during autoclaving. Endocrinology 132: 2279-2286, 1993.

16 Perez P, Pulgar R, Olea-Serrano F, Villalobos M, Rivas A, Metzler M, Pedraza V and Olea N: The estrogenicity of bisphenol Arelated diphenylalkanes with various substituents at the central carbon and the hydroxyl group. Environ Health Perspect 106: 167174, 1998.

17 Hashimoto, Y, Moriguchi Y, Oshima H, Kawaguchi M, Miyazaki $\mathrm{K}$ and Nakamura M: Measurement of estrogenic activity of chemicals for the development of new dental polymers. Toxicology In Vitro 15: 421-425, 2001.

18 Zhu H, Xiao X, Zheng J, Zheng S, Dong K and Yu Y: Growthpromoting effect of bisphenol A on neuroblastoma in vitro and in vivo. J Pediatr Surg 44: 672-680, 2009.

19 Soto AM, Justicia H, Wray JW and Sonnennschein C: $p$ Nonylphenol: an estrogenic xenobiotic released from "modified" polystyrene. Environ Health Perspect 92: 167-173, 1991.

20 White R, Jobling S, Hoare SA, Sumpter JP and Parker MG: Environmentally persistent alkylphenolic compounds are estrogenic. Endocrinology 135: 175-182, 1994.

21 Choi EJ, Jung JY and Kim G-H: Genistein inhibits the proliferation and differentiation of MCF-7 and 3T3-L1 cells via the regulation of ER $\alpha$ expression and induction of apoptosis. Exp Ther Med 8: 454-458, 2014.

22 Record IR, Broadbent JL, King RA, Dreosti IE, Head RJ and Tonkin AL: Genistein inhibits growth of B16 melanoma cells in vivo and in vitro and promotes differentiation. Int $\mathrm{J}$ Cancer 72 : 860-864, 1997.

23 Dome JS and Schwartz CL: Osteosarcoma. Cancer Treat Res 92: 215-251, 1997.

24 Bacci G, Longhi A, Versari M, Mercuri M, Briccoli A and Picci P: Prognostic factors for osteosarcoma of the extremity treated with neoadjuvant chemotherapy: 15-year experience in 789 patients treated at a single institution. Cancer 106: 1154-1161, 2006.

25 Bacci G, Briccoli A, Ferrari S, Saeter G, Donati D, Longhi A, Manfrini M, Bertoni F, Rimondini S, Monti C and Forni C: Neoadjuvant chemotherapy for osteosarcoma of the extremities with synchronous lung metastases: treatment with cisplatin, adriamycin and high dose of methotrexate and ifosfamide. Oncol Rep 7: 339-346, 2000.

26 Saeter G, Høie J, Stenwig AE, Johansson AK, Hannisdal E and Solheim OP: Systemic relapse of patients with osteogenic sarcoma: Prognostic factors for long term survival. Cancer 75: 1084-1093, 1995.

27 Asai T, Ueda T, Itoh K, Yoshioka K, Aoki Y, Mori S and Yoshikawa H: Establishment and characterization of a murine osteosarcoma cell line (LM8) with high metastatic potential to the lung. Int J Cancer 76: 418-422, 1998.

28 Kamei S, Sakayama K, Tamashiro S, Aizawa J, Miyawaki J, Miyazaki T, Yamamoto H, Norimatsu Y and Masuno H: Ketoprofen in topical formulation decreases the matrix metalloproteinase-2 expression and pulmonary metastatic incidence in nude mice with osteosarcoma. J Orthop Res 27: 909-915, 2009.
29 Aizawa J, Sakayama K, Kamei S, Kidani T, Yamamoto H, Norimatsu Y and Masuno H: Effect of troglitazone on tumor growth and pulmonary metastasis development of the mouse osteosarcoma cell line LM8. BMC Cancer 10: 51, 2010.

30 Nakamura A, Aizawa J, Sakayama K, Kidani T, Takata T, Norimatsu Y, Miura H and Masuno H: Genistein inhibits cell invasion and motility by inducing cell differentiation in murine osteosarcoma cell line LM8. BMC Cell Biol 13: 24, 2012.

31 Hinegardner RT: An improved fluorometric assay for DNA. Anal Biochem 39: 197-201, 1971.

32 Boureux A, Vignal E, Faure S and Fort P: Evolution of the Rho family of Ras-like GTPases in eukaryotes. Mol Biol Evol 24: 203216, 2007.

33 Nobes CD and Hall A: Rho, Rac, and CDC42 GTPases regulate the assembly of multimolecular focal complexes associated with actin stress fibers, lamellipodia, and filopodia. Cell 81: 53-62, 1995.

34 Krugmann S, Jordens I, Gevaert K, Driessens M, Vandekerckhove $\mathrm{J}$ and Hall A: CDC42 induces filopodia by promoting the formation of an IRSp53:Mena complex. Cur Biol 11: 1645-1655, 2001.

35 Stetler-Stevenson WG, Aznavoorian S and Liotta LA: Tumor cell interactions with the extracellular matrix during invasion and metastasis. Annu Rev Cell Biol 9: 541-573, 1993.

36 Kusuzaki K, Takeshita H, Murata H, Hashiguchi S, Nozaki T, Emoto K, Ashihara T and Hirasawa Y: Bionuclear cells induced by acridine orange in giant cell tumor of bone. Anticancer Res 20 : 3013-3018, 2000.

37 Taniguchi K, Kokuryo A, Imano T, Minami R, Nakagoshi H and Adachi-Yamada T: Isoform-specific functions of Mud/NuMA mediate binucleation of Drosophila male accessory gland cells. BMC Develop Biol 14: 46, 2014.

38 Kidani T, Kamei S, Miyawaki J, Aizawa J, Sakayama K and Masuno H: Bisphenol A down-regulates AKT signalling and inhibits adiponectin production and secretion in 3T3-L1 adipocytes. J Atheroscler Thromb 17: 834-843, 2010.

39 Yui Y, Itoh K, Yoshioka K, Naka N, Watanabe M, Hiraumi Y, Matsubara H, Watanabe K, Sano K, Nakahata T and Adachi S: Mesenchymal mode of migration participates in pulmonary metastasis of mouse osteosarcoma LM8. Clin Exp Metastasis 27: 619-630, 2010.

40 Fukuda H, Nakamura S, Chisaki Y, Takada T, Toda Y, Murata H, Itoh K, Yano Y, Takata K and Ashihara E: Daphnetin inhibits invasion and migration of LM8 murine osteosarcoma cells by decreasing RhoA and CDC42 expression. Biochem Biophys Res Commun 471: 63-67, 2016.

41 Kleiner DE and Stetler-Stevenson WG: Matrix metallo-proteinases and metastasis. Cancer Chemother Pharmacol 43(Suppl): S42-51, 1999. 